\title{
Grading Evaluation of the Structural Connectivity of River System Networks Based on Ecological Functions, and a Case Study of the Baiyangdian Wetland, China
}

\author{
Kai Tian ${ }^{1,2}$, Xin-an Yin ${ }^{1,2}$, Jie Bai ${ }^{1,2}$, Wei Yang ${ }^{1,2}$ and Yan-wei Zhao ${ }^{1,2, *}$ \\ 1 State Key Laboratory of Water Environment Simulation, Beijing Normal University, Beijing 100875, China; \\ 201731180022@mail.bnu.edu.cn (K.T.); yinxinan@bnu.edu.cn (X.-a.Y.); 201921180044@mail.bnu.edu.cn (J.B.); \\ yangwei@bnu.edu.cn (W.Y.) \\ 2 School of Environment, Beijing Normal University, Beijing 100875, China \\ * Correspondence: awei1974@bnu.edu.cn; Tel./Fax: +86-10-5880-1719
}

check for updates

Citation: Tian, K.; Yin, X.-a.; Bai, J.; Yang, W.; Zhao, Y.-w. Grading Evaluation of the Structural

Connectivity of River System Networks Based on Ecological Functions, and a Case Study of the Baiyangdian Wetland, China. Water 2021, 13, 1775. https://doi.org/ 10.3390/w13131775

Academic Editor: Rui Cortes

Received: 9 April 2021

Accepted: 23 June 2021

Published: 27 June 2021

Publisher's Note: MDPI stays neutral with regard to jurisdictional claims in published maps and institutional affiliations.

Copyright: (c) 2021 by the authors. Licensee MDPI, Basel, Switzerland. This article is an open access article distributed under the terms and conditions of the Creative Commons Attribution (CC BY) license (https:// creativecommons.org/licenses/by/ $4.0 /)$.

\begin{abstract}
River system network (RSN) connectivity is important to maintain the environmental and ecological functions of wetlands. Quantitative evaluation of connectivity can provide crucial support for efforts to improve wetland connectivity and to restore and protect wetland ecosystems. Most existing evaluation methods uniformly generalise RSN to form an undifferentiated RSN of edges and nodes that is taken as a whole to evaluate the connectivity. However, actual RSNs comprise rivers, canals, ditches, lakes, and ponds, which differ substantially in their structures, morphologies, and attributes. The mix of RSN elements therefore defines grades that give RSNs distinctive characteristics. Moreover, RSNs with different grades perform different ranges of environmental and ecological functions. The existing evaluation methods, which have some limitations, do not account for these characteristics. To account for these differences, we examined the grade characteristics and their impact on environmental and ecological functions. We established a grading system of RSN elements and a grading method of RSN, and constructed the structural connectivity evaluation indicator system for RSNs at different grades. On this basis, we propose a method for grading evaluation of RSN connectivity. We used China's Baiyangdian Wetland to demonstrate the use of the system and validate the results. The proposed method provided an objective and accurate evaluation of RSN connectivity and clarified the differences in connectivity among RSNs with different grades, thereby providing improved guidance for the development and maintenance of the environmental and ecological functions of RSNs.
\end{abstract}

Keywords: connectivity evaluation; structural connectivity; grade of river system networks; ecological functions of river system networks; Lake Baiyangdian

\section{Introduction}

Wetlands are one of the most biologically diverse, productive, and valuable ecosystems on Earth [1]. In recent years, the interference of human activities such as hydropower plant construction, water diversion projects and aquaculture have changed the wetland structure, ecological environment and function greatly [2]. Under the dual effects of nature and human interventions, various types of rivers, canals, ditches, lakes, and ponds have formed inside some wetlands, leading to the development of complex river system networks [3]. These networks play important support roles for wetland processes such as water flow and nutrient circulation, and the strength of a network's connectivity is directly related to wetland health and ecosystem stability [4]. Because connectivity is an important factor for maintaining wetland ecological functions, it also affects hydrology, water quality, and aquatic ecology, thereby playing a critical role in the development and ecological succession of wetland ecosystems [5]. Much research on improving the connectivity of river system networks and restoring the ecological functions of networks 
by restoring environmental flow, strengthening the water cycle and mitigating the impact of human activities has also received increasing attention [6]. Favourable connectivity effectively promotes cycling of energy and nutrients, and therefore promotes and maintains biodiversity. The scientific evaluation of wetland connectivity can support the development of ecological water networks and improve water continuity, which is crucial for protecting wetland ecosystems.

Connectivity evaluation constitutes an indispensable part of river-system network research. Many studies have been performed from multiple perspectives, which has resulted in the formation of a relatively complete system of methods for connectivity evaluation. Current evaluation methods mainly include in situ monitoring, approaches based on graph theory, hydrological models, connectivity functions, and comprehensive multi-indicator evaluation methods. The in situ monitoring method uses monitoring stations at river intersections or river-lake intersections to obtain hydrological monitoring data that will quantify connectivity using data such as the time when a given volume of water passes and the water level duration. In situ monitoring is simple and intuitive; however, it requires a large amount of data. Thus, it is most suitable for small watersheds and simple networks. Schiemer et al. [7] applied the time of water passing to analyse connectivity in a section of the Danube River network. Lesack and Marsh [8] evaluated the connectivity of rivers and lakes based on the duration for which the river level exceeded the lake level. Graph theory approaches are based on unified generalisation of a network to extract a digital representation, which allows analysis of geometric topological relationships among the network's nodes and edges to evaluate connectivity; these approaches are suitable for assessing connectivity between the main channel and branches of a river and between lakes and rivers [9]. Cui et al. [10] and Zhou et al. [11] employed the shortest-path algorithm and connectivity theory to evaluate connectivity. Hydrological models are based on generalised extracted networks, and are used to simulate a network's main hydrological processes to evaluate connectivity between or within wetlands based on the key parameters that affect these processes. Due to limitations of model accuracy and long calculation times, this approach is most suitable for small networks of rivers and lakes. Bracken and Croke [12] used the Climate Runoff Position Pathway Lateral (CRPPL) connectivity model to study connectivity between a network's large and small hydrological units. Lane et al. [13] applied the Physically Distributed Hydrological Model (PDHM) to quantify connectivity between rivers and lakes in a wetland. The connectivity function method is employed to establish a connectivity index that reflects the influences of landscape dynamic changes on connectivity. This method is used to evaluate the overall connectivity of wetlands and is suitable for characterizing variations in the overall connectivity caused by different landscape dynamics. Meerkerk et al. [9] used a connectivity function to analyse how terrace reduction and disappearance affected hydrological connectivity in semi-arid basins. Liu et al. [14] proposed an index to evaluate connectivity in Poyang Lake. In the multi-indicator comprehensive evaluation method, researchers select multiple indicators of the natural and social attributes of wetlands and use them to evaluate the network's connectivity [15]. This method includes indicators related to network patterns, structures, and functions. Chen et al. [16] established an evaluation indicator system for river-lake network connectivity. By establishing an indicator system, Chen and Wang [17] assessed changes in the connectivity of the Yellow River Basin from 1960 to 2015. Based on the network's characteristics, many multiscale and multifaceted studies have been conducted, which have further improved and enriched the evaluation methods for these networks and have provided support for studies on wetland connectivity and on network maintenance and improvement.

Most of the aforementioned evaluation methods are used to uniformly generalise river system networks, and they consider rivers and canals as edges (i.e., lines that connect nodes in the network) and lakes and intersections as nodes. However, they do not distinguish among bodies of water based on their length, depth, area, water level, and other attributes, and evaluate connectivity as an overall value. Uniform generalisation of a river system 
network into a network composed of nodes and edges can simplify the structural relationships of networks and can help to reveal problems in the network's structure and layout. However, actual river networks are composed of a mixture of rivers, canals, ditches, lakes, and ponds, which have great differences in their structures, morphologies, and attributes. Large rivers and small tributaries, and large lakes and small ponds have remarkably different characteristics; the elements of the network therefore have obvious differences that can be defined as grade characteristics, such as wide versus narrow and long versus short [18]. The elements with substantial differences are connected to each other in complicated ways within these networks. There are huge differences among networks composed of large rivers and large lakes, of large rivers and small lakes, and of small tributaries and small ponds; therefore, river system networks have apparent characteristics that can be used to classify them into grades [19]. Networks with different grades correspond to different complexities, with different changes in hydrological rhythms and hydrodynamics that affect material migration and transformation [20], and differences in water purification processes, such as convective dilution and sedimentation adsorption [21]. These differences also affect biological habitats and influence biological colonisation, propagation, and wetland biodiversity [22], and affect the survival of organisms such as wetland plants, zooplankton, and fish [23]. Networks with different grades result in different intensities of connectivity between wetland patches, and these differences determine the strength of the network's functional connectivity and its ability to resist external interference [24], thereby affecting the population structure of species such as fish and birds as well as the integrity and stability of the network's ecosystems [25]. The network grade is therefore closely related to the hydrologic network's environmental and ecological functions, and networks that have different grades perform different environmental and ecological functions or the same functions but with different intensities. However, networks that are acquired from the unified generalisation that is provided using current evaluation methods fail to account for these grades and the associated differences in the network's environmental and ecological functions. The networks therefore have limitations in their ability to account for the abovementioned differences.

In this paper, our goal is to establish a grading evaluation method of the connectivity of the river network system, which can more scientifically evaluate the connectivity state of wetland, and provide support for the wetland ecological environment protection and restoration. As a result, we thoroughly considered the grade characteristics of river system networks and differences in their environmental and ecological functions to establish a grading system for network elements and a grading method for networks, then constructed a structural connectivity evaluation indicator system. Based on this framework, we propose a method for evaluating a network's connectivity while accounting for its environmental and ecological functions. We selected China's Baiyangdian Wetland as a study area and used the proposed evaluation method to demonstrate the grading evaluation of structural connectivity. Based on the results of this evaluation, we compared the proposed method with currently available evaluation methods, and demonstrated the objectivity and applicability of the proposed method.

\section{Methods}

\subsection{Grading and Extraction of Networks}

In order to identify the components of the network, we needed to use remote sensing images to obtain data. When selecting remote sensing images, we tried to select the image data with smaller cloud cover and higher resolution, and for the image time selected the dry season with small water volume and low water level, which is conducive to the identification of the river-system network elements. When performing remote-sensing interpretation, different interpretation methods should be adopted for different study areas, and multiple interpretation methods such as manual visual interpretation, automatic image interpretation and maximum-likelihood supervised classification should be used flexibly. We identified key elements of the river system network, such as rivers, canals, shallow 
lakes, and ponds, and obtained data about their attributes, including their length, width, and area. Based on the terrain data, we acquired data such as depth and elevation. We then divided the different morphological structures into two categories: rivers, canals, and ditches were classified as channel elements, and shallow lakes and ponds were classified as lake elements.

\subsubsection{Grading of Elements}

The differences in the environmental and ecological functions of the network are affected by many factors, such as discharge, velocity, width, depth, and area of the network elements, and among these, the attributes such as width, depth, and area are the direct causes of differences in the environmental and ecological functions of networks with different grades [26] (Table 1). We focused on structural morphology and did not account for other factors. We established a grading system for the elements that accounts for differences in the width, depth, and area of the elements. The width and depth are used as the channel element grading indexes, and the area and depth are used as the lake element grading indexes. The channel and lake elements can then be divided into different grades that reflect their range of values.

Table 1. Grading indexes of network elements and their data acquisition and application.

Name

Connotation

\section{Relationship between Structural \\ and}

Functions
Acquisition and Application
There is a relationship between the width, water level, and water flow of a river, with the minimum width corresponding to the minimum ecological flow and water level [27].

The width of a ditch affects its pollutant removal efficiency [28]. River width is one of the important indicators to evaluate the suitability of fish habitat, which is directly related to fish biodiversity [29].

River size affected the effect on fish abundance/biomass increased with river width [30].

Habitat-specific factors such as hydrology, depth, turbidity and geomorphology significantly influence the species composition and abundance in river systems [31].

The structural depth of channel elements such as rivers, canals, and ditches.

Depth
The average structural depth of lake elements such as shallow lakes and ponds.
The data is obtained through high-precision remote sensing image measurement or on-site surveying and mapping. According to the relationship between width and function, the standard of element grading is established, that is, the width threshold corresponding to different grade channel elements. When the channel width belongs to which threshold, the channel should be divided into the grade A or B or C*.

The data needs to be obtained through measured terrain data. By analyzing the relationship between the channel depth and the ecological or environmental function, the standard of element grading is established, that is, the depth threshold corresponding to different grade elements. When the channel depth belongs to which threshold, the channel should be divided into the grade $\mathrm{A}$ or $\mathrm{B}$ or $\mathrm{C}^{*}$. chemical variables that contribute to organizing fish assemblages in shallow lakes. [33]. 
Table 1. Cont.

\begin{tabular}{|c|c|c|c|}
\hline Name & Connotation & $\begin{array}{c}\text { Relationship between Structural } \\
\text { and } \\
\text { Functions }\end{array}$ & Acquisition and Application \\
\hline Area & $\begin{array}{l}\text { The area of lake elements such as } \\
\text { shallow lakes and ponds. }\end{array}$ & $\begin{array}{l}\text { Area directly affects the wetland's } \\
\text { contribution in removing } \\
\text { pollutants [34]. } \\
\text { Lake area is an important index to } \\
\text { evaluate waterfowl habitat, which } \\
\text { is directly related to their survival } \\
\text { and biodiversity, especially in } \\
\text { shallow lake wetlands [35]. } \\
\text { Zooplankton species richness } \\
\text { often increases as a linear function } \\
\text { of lake area, possibly because } \\
\text { habitat diversity increases with } \\
\text { lake size [36]. }\end{array}$ & $\begin{array}{l}\text { The data is obtained through } \\
\text { high-precision remote sensing } \\
\text { image measurement or on-site } \\
\text { surveying and mapping. } \\
\text { By analyzing the relationship } \\
\text { between the lake element area } \\
\text { and the ecological or } \\
\text { environmental function, the } \\
\text { standard of element grading is } \\
\text { established, that is, the area } \\
\text { threshold corresponding to } \\
\text { different grade elements. When } \\
\text { the lake area belongs to which } \\
\text { threshold, the lake should be } \\
\text { divided into the grade } \\
\text { A or B or C }{ }^{*} \text {. }\end{array}$ \\
\hline
\end{tabular}

Note: grade $\mathrm{A}$ or $\mathrm{B}$ or $\mathrm{C}^{*}$ is the grade type of the element we assume, and does not represent any specific or actual grade system.

\subsubsection{Grading of Networks}

By performing different environmental and ecological functions, networks with different grades jointly promote the exchange and circulation of matter, energy, and information in wetlands and maintain their health, thereby permitting sustainable development. For connectivity evaluation, networks should be graded so that they group multiple characteristics into a single descriptive index.

We assume that the channel elements and lake elements are divided into three grades: A, B, and C based on their differences in width, depth, and area. The grade A channel elements and grade $\mathrm{A}$ lake elements are connected to form a grade $\mathrm{A}$ water system network; the grade $\mathrm{B}$ channel elements and grade $\mathrm{B}$ lake elements are connected to form a grade $\mathrm{B}$ water system network; and the grade $C$ network is formed by the grade $C$ elements. Their order is grade $\mathrm{A}>$ grade $\mathrm{B}>$ grade $\mathrm{C}$. The rules for the formation of grading networks can be summarized in the following three steps. To follow the order, we complete grading of the network in turn.

(1) First, we need to extract the constituent elements of the network. For example, when forming the grade A network, grade A channel elements and lake elements need to be extracted. The grade $B$ and $C$ networks should be done in the same manner.

(2) Second, we identify and judge the simple connected form in the network-two lake elements are linked by the channel elements. In one grade network, if two lake elements of that grade are linked by the channel higher than that grade or of the same grade, the two lake elements are considered to be connected; on the contrary, if they are linked by the channel lower than this grade, it is judged as disconnected. For example, when a grade B network is formed, if two grade B lake elements are linked by a grade A or grade B channel, it is judged to be connected; if they are linked by a grade $C$ channel it is judged as disconnected, see Figure 1. Check the entire network according to this rule.

(3) Third, we identify and judge the complex connected form-two lake elements linked by a combination of channel and lake elements. When the grading forms the grade $\mathrm{B}$ network, the lakes and channels of grade $B$ are the main body of the network. The complex connected form of grade B lake-channel-grade A or C lake-channel-grade $B$ lake, the grade $A$ or $C$ lake should be transformed into the higher grade channel connected with it, and then we can judge whether two grade B lakes are connected or not by rule 2. For example, in Figure 2a, it is a complex connected form of grade B 
lake-grade A channel-grade A lake-grade B channel-grade B lake. To judge whether the two grade $B$ lakes are connected, the grade $A$ lake should be transformed into the grade A channel connected with it. Such a complex connected form becomes a simple connected form, that is, the grade B lake-grade A channel-grade A channel-grade B channel-grade B lake; two grade B lakes are connected by the high-grade channels, according to rule 2 , and therefore the two grade $B$ lakes are connected. In Figure $2 b$, the complex connected form of the grade $B$ lake-grade B channel-grade A lake-grade $C$ channel-grade $B$ lake should be transformed into the simple connected form of the grade B lake-grade B channel-grade B channel-grade C channel-grade B lake. There are grade $C$ channels in the connection, which indicates that the two grade $B$ lakes are connected by low-grade channels, so they are disconnected. According to this rule, the various complex connected forms in the network can be judged, and finally the grading of the network can be completed.

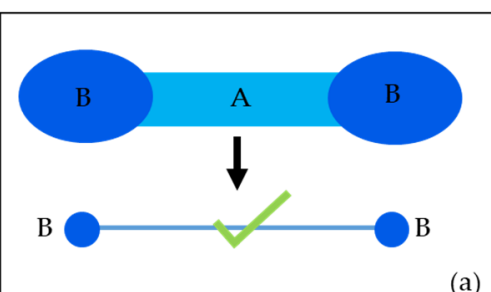

(a)

Legend A Channel elemen

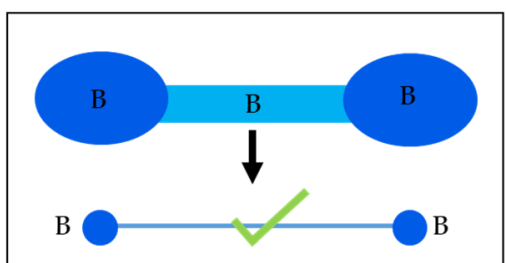

(b)

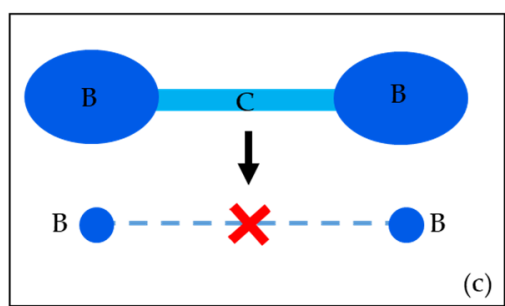

(c)

Figure 1. Judgment of the simple connected form. $(\mathbf{a}-\mathbf{c})$ represents simple connected forms of different grades. Grade A, B and $\mathrm{C}$ mean that the network elements (lakes and channels) are divided into different grades according to Table 1.
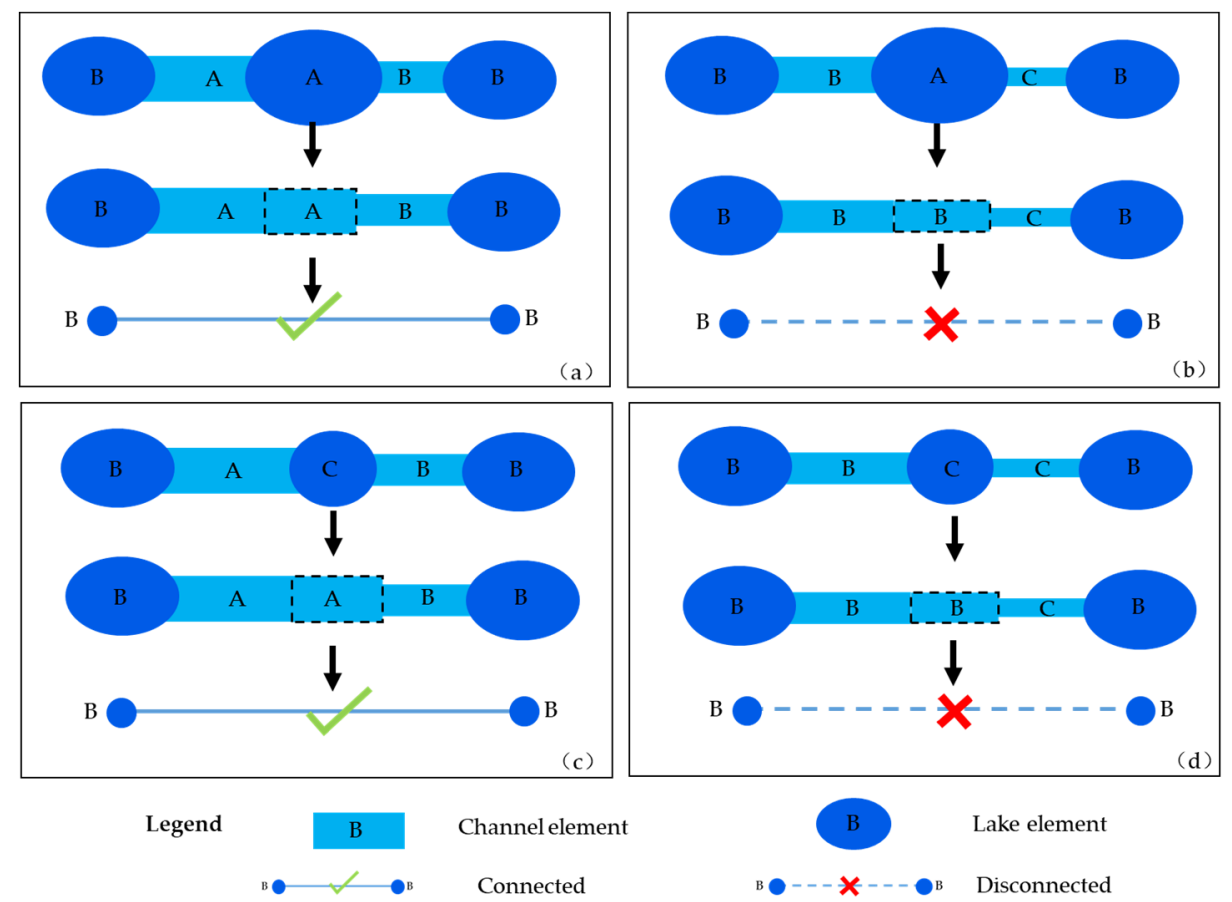

Figure 2. Judgment of the complex connected form. (a-d) represents the different complex connected forms. Grade A, B and C mean that the network elements (lakes and channels) are divided into different grades according to Table 1.

\subsubsection{Extraction of Networks}

We generalised and extracted the network using ArcGIS 10.5 (https:/ /www.esri.com, accessed date on 13 April 2020). The channel elements were generalised as edges, and the 
lake elements and intersections of the channel elements were generalised as nodes. The central line for each channel element was extracted to define the position of the edge, and the centroid of each lake element was extracted as the node's position. Based on the grading results, edges and nodes together constitute a network with topological relationships of different grades (Figure 3).

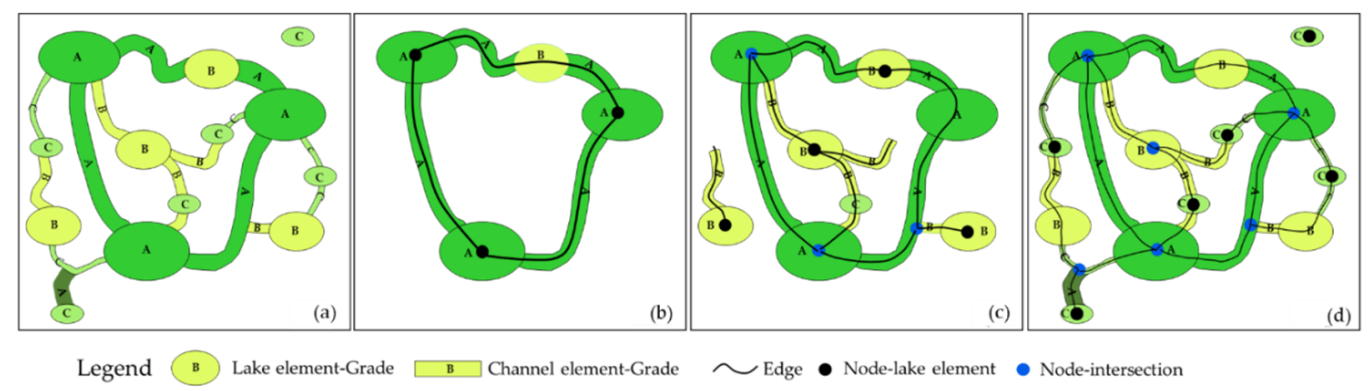

Figure 3. Graduation and extraction of river system networks: (a) natural wetlands, and networks that include elements with grades (b) A, (c) B, and (d) C. Grade A, B and C mean that the network elements (lakes and channels) are divided into different grades according to Table 1.

\subsection{Evaluation of Structural Connectivity}

\subsubsection{Development of the Indicator System}

When establishing a structural connectivity evaluation indicator system, it is necessary to consider natural attributes such as the morphology, spatial distribution, and structural composition of network elements (waterways, ditches, and lakes) as well as the function of connection and exchange as the network itself, while as the water flow carrier, the river system network should have a certain ability to accommodate water circulation and movement. Based on the characteristics of the network in the wetland, we also fully absorbed the experience and results of many researchers on the evaluation of the network connectivity. From the three aspects of the layout of the network, connectivity of the network and smoothness of water flow, we selected 7 indicators to establish the structural connectivity evaluation indicator system. In terms of layout of the network, the focus is to evaluate the combination status and development degree of waterways, ditches, and lakes in different grade networks. The two indicators of lake density and frequency of channels are the two key elements of the combination status of the network, and they can respectively reflect the degree of development of rivers and lakes; the greater the density, the stronger the trend of better connectivity is [37]. In the river system network, nodes are lakes and intersections, and edges represent connecting channels. The exchange capacity and interconnection status of each edge and node are important factors that affect the connectivity of the river system network [15]. In terms of network connectivity, the focus is to evaluate the exchange capacity and connectivity of nodes and edges in different grade networks. The loop ratio of a network essentially is the number and proportion of edge connections between nodes, which directly reflects the exchange capacity of nodes. Node connection rate represents the proportional relationship between the number of nodes and the number of edges; the network with a high node connection rate commonly has a developed stream network, and each lake occupies more rivers. For the connected network, a node connection rate less than 1 indicates that the network is too thin; each lake on average occupies less than 1 river, and there is no ring structure to circulate water in the network. The edge connectivity ratio can precisely reflect the extent of the weakest link and area in the stream network and use it to represent the connectivity of the entire system, which is the determinant index in an evaluation system. Network connectedness reflects the connectivity of the edges in the network through the logarithm ratio of connected nodes. The more connected nodes, the better the connectivity of the edges. Different attributes such as the width, depth, length, and slope of the channel in the river system network have different effects on the network connectivity, which directly affect the exchange rate of the 
flow rate, material and energy [38]. Smoothness of water flow is to use the width, depth and slope parameters of the channel to reflect the flow, material and energy exchange rate of the network, which can directly evaluate the overall connectivity of the network. All indicators are shown in Table 2.

Table 2. Structural connectivity evaluation indicators.

\begin{tabular}{|c|c|c|c|c|c|}
\hline Order & Layers & Indicators & Definition & Equation & Unit \\
\hline 1 & \multirow[t]{2}{*}{$\begin{array}{l}\text { Layout of } \\
\text { the network }\end{array}$} & $\begin{array}{l}\text { Density of } \\
\text { lake } \\
\text { elements } \\
(L D)\end{array}$ & $\begin{array}{c}\text { The area of lake elements per } \\
\text { unit area }\end{array}$ & $\begin{array}{l}\qquad L D=\frac{L A}{A} \\
\text { where } L A \text { denotes the area } \\
\text { covered by lake elements and } A \\
\text { represents the total study area. }\end{array}$ & Dimensionless \\
\hline 2 & & $\begin{array}{c}\text { Frequency of } \\
\text { channel } \\
\text { elements } \\
\left(C_{f}\right)\end{array}$ & $\begin{array}{l}\text { The number of channel } \\
\text { elements per unit area }\end{array}$ & $\begin{array}{l}\qquad C_{f}=\frac{C N}{A} \\
\text { where } C N \text { refers to the number } \\
\text { of channel elements and } A \\
\text { represents the total study area. }\end{array}$ & $\mathrm{km}^{-2}$ \\
\hline 3 & \multirow{4}{*}{$\begin{array}{l}\text { Connectivity of } \\
\text { the network }\end{array}$} & $\begin{array}{l}\text { Loop ratio of } \\
\text { network } \\
(\alpha)\end{array}$ & $\begin{array}{l}\text { The ratio of the actual number } \\
\text { of loops to the maximum } \\
\text { number of possible loops in the } \\
\text { network, which reflects the } \\
\text { material and energy exchange } \\
\text { capacity of a node. }\end{array}$ & $\begin{array}{l}\qquad \alpha=\frac{E-N+1}{2 N-5} \\
\text { where } E \text { denotes the number of } \\
\text { edges and } N \text { is the number } \\
\text { of nodes. }\end{array}$ & Dimensionless \\
\hline 4 & & $\begin{array}{l}\text { Node } \\
\text { connection } \\
\text { rate } \\
(\beta)\end{array}$ & $\begin{array}{l}\text { How easy it is for each node to } \\
\text { connect to other nodes. }\end{array}$ & $\begin{array}{l}\qquad \beta=\frac{2 E}{N} \\
\text { where } E \text { denotes the number of } \\
\text { edges and } N \text { is the number } \\
\text { of nodes. }\end{array}$ & Dimensionless \\
\hline 5 & & $\begin{array}{l}\text { Edge } \\
\text { connectivity } \\
\text { ratio } \\
(C P)\end{array}$ & $\begin{array}{l}\text { The ratio of the number of } \\
\text { connected node pairs to the } \\
\text { total number of node pairs, } \\
\text { which reveals the connectivity } \\
\text { of edges from the number of } \\
\text { connected nodes. }\end{array}$ & $\begin{array}{l}\qquad C P=\frac{C N_{p}}{N_{p}} \\
\text { where } C N_{p} \text { denotes the number } \\
\text { of connected node pairs and } N_{p} \\
\text { denotes the total number of } \\
\text { node pairs. }\end{array}$ & Dimensionless \\
\hline 6 & & $\begin{array}{l}\text { Network } \\
\text { connected- } \\
\text { ness } \\
(\gamma)\end{array}$ & $\begin{array}{l}\text { The ratio of the number of } \\
\text { connected channels to the } \\
\text { maximum number of possibly } \\
\text { connected channels. }\end{array}$ & $\begin{array}{l}\quad \gamma=\frac{E}{L_{\max }}=\frac{E}{3(N-2)} \\
(N \geq 3) \\
\text { where } E \text { denotes the number of } \\
\text { edges, } N \text { denotes the number of } \\
\text { nodes, and } L_{\max } \text { represents the } \\
\text { maximum number of edges that } \\
\text { are possibly connected. }\end{array}$ & Dimensionless \\
\hline 7 & $\begin{array}{l}\text { Smoothness of } \\
\text { the network }\end{array}$ & $\begin{array}{l}\text { Smoothness } \\
\text { of } \\
\text { water flow } \\
(\omega)\end{array}$ & $\begin{array}{l}\text { The unobstructed degree of } \\
\text { water flow, which equals the } \\
\text { reciprocal of the resistance to } \\
\text { water flow. }\end{array}$ & $\begin{array}{l}\qquad \omega=\ln \left[\frac{(b+m h) h}{b+2 h \sqrt{1+m^{2}}}\right]-\frac{2}{3} \\
\text { where } b \text { denotes bottom width } \\
\text { of the channel element, } h \text { is the } \\
\text { depth of the channel element, } \\
\text { and } m \text { represents the } \\
\text { slope coefficient. }\end{array}$ & Dimensionless \\
\hline
\end{tabular}

\subsubsection{Weight Determination}

We determined the weight of each indicator using a combination of the analytic hierarchy process [39] and the entropy-weight method. The analytic hierarchy process uses the subjective experience of experts to quantify the weight, and has the advantage of simplifying complex objective problems. The weight is recorded as $W_{1 j}$ for element $j$.

The entropy-weight method is an objective weighting method that tries to eliminate the subjectivity that is inherent to human opinions [40]; this weight is denoted $W_{2} j$. The weight of each indicator was calculated based on the differences between indexes; the specific steps are as follows: 
(1) Normalization

$$
p_{i j}=\frac{x_{i j}}{\sum_{i=1}^{m} x_{i j}}
$$

(2) Index Entropy

$$
E_{j}=\frac{1}{\ln m} \sum_{i=1}^{m} p_{i j} \ln p_{i j}
$$

(3) Index Weight

$$
W_{2 j}=\frac{1-E_{j}}{\sum_{j=1}^{n}\left(1-E_{j}\right)}
$$

where: $n$ denotes the number of indexes, $m$ represents the number of evaluated objects, $x_{i j}$ stands for the attribute value of the $j$-th index of the $i$-th evaluated object, $p_{i j}$ represents the normalized value of the indicator, and $E_{j}$ refers to the entropy of the $j$-th index.

The comprehensive weight, recorded as $W_{j}$, was obtained by coupling $W_{1 j}$ and $W_{2 j}$ through multiplier normalisation. By combining both subjective and objective factors, this comprehensive weight can be used to mitigate errors that result from either of the two component judgments.

$$
W_{j}=\frac{W_{1 j} W_{2 j}}{\sum_{j=1}^{n} W_{1 j} W_{2 j}}
$$

where: $W_{j}$ is the comprehensive weight, $W_{1 j}$ is the weight determined by analytic hierarchy process, $W_{2 j}$ the weight determined by entropy-weight method.

\subsubsection{Structural Connectivity Index}

Based on the indicator values and weights, we calculated the structural connectivity index I for each grade of network as follows:

$$
I=W_{1} L D+W_{2} C_{\mathrm{f}}+W_{3} \alpha+W_{4} \beta+W_{5} C P+W_{6} \gamma+W_{7} \omega
$$

where $W_{1}$ to $W_{7}$ denote the comprehensive weights $\left(W_{j}\right)$ of indicators 1 to 7 in Table 2 .

\section{Case Study}

\subsection{Study Area}

The Baiyangdian Wetland is located between $115^{\circ} 38^{\prime} \mathrm{E}$ and $116^{\circ} 07^{\prime} \mathrm{E}$ and between $38^{\circ} 43^{\prime} \mathrm{N}$ and $39^{\circ} 02^{\prime} \mathrm{N}$, and covers a total area of $366 \mathrm{~km}^{2}$. It comprises the confluence of nine rivers and is a typical grass-type shallow lake in northern China. The wetland comprises many lakes and ponds of different sizes along with crisscrossing rivers, canals, and ditches. The area of shallow lakes and ponds has remained approximately $150 \mathrm{~km}^{2}$ for many years, and the total area of rivers, canals, and ditches is approximately $25 \mathrm{~km}^{2}$. These bodies of water are connected by rivers, canals, lakes, and ponds that constitute the wetland's river system network. That network is composed of networks with different grades, which perform different hydrological, environmental, and ecological functions and play an important role in flood control, water storage, water purification, and biodiversity protection.

\subsection{Grading Results}

We used 2.4-m-resolution remote sensing images obtained from the GF-2 satellite. The images were captured on 27 March 2019 and cloud volume was less than 5\%. We chose this date because it represented the period of the year with the minimum annual vegetation cover, which helped us to better identify various water bodies. We used version 5.4 of the ENVI software (https:/ / www.l3harrisgeospatial.com/, accessed date on 13 April 2020) and version 10.5 of the ArcGIS software (https:/ / www.esri.com, accessed date on 13 April 2020) to interpret the remote sensing images. Due to the small scale of many ditches, waterways and lakes in the Baiyangdian Wetland, the width of which is not more than 
$5 \mathrm{~m}$, other interpretation methods are difficult to meet the requirements, so we used the method of manual visual interpretation to identify the elements and verified the imageinterpretation results in the field in October 2019. We identified 598 channel elements and 173 lake elements. We calculated their width and area attributes based on the field measured data of network elements and remote-sensing interpretation results. Based on the 1:2000 topographic data measured on-site, we calculated the depth and elevation data for the hydrologic network elements.

\subsubsection{Grading of Network Elements}

As the largest shallow-lake ecosystem in North China, the Baiyangdian Wetland is the habitat for many fish and rare waterfowl [41]. Fish in the Cypriniformes order, such as Cyprinus carpio, Carassius auratus, Ctenopharyngodon idellus, Aristichthys nobilis, Hemiculter leucisculus, and Pseudorasbora parva, etc., are the primary fish living in the Baiyangdian Wetland, where they account for approximately $66 \%$ of the total fish numbers [42]. Among the waterfowl, Chlidonias hybrida and Acrocephalus orientalis are the most representative species in the wetland [43]. Fish are highly selective about the depth and width of rivers and canals that they prefer [44], and waterfowl are extremely sensitive to changes in the depth and area of lakes and ponds [45].

We set up 20 points (11 channel element monitoring points, 9 lake element monitoring points) in the Baiyangdian Wetland, as shown in Figure 4, to obtain fish monitoring data, combined with the title "The rapid assessment in research of wild fish resource in the Baiyangdian Wetland and sustainable utilization" report [46], using statistical analysis methods to fit the relationship curve between the width, depth, and area of the network elements and the fish species richness (Tables 3 and 4, Figure 5), and to analyze dominant species in ditches, waterways, ponds, and shallow lakes of various sizes (Tables 5 and 6).

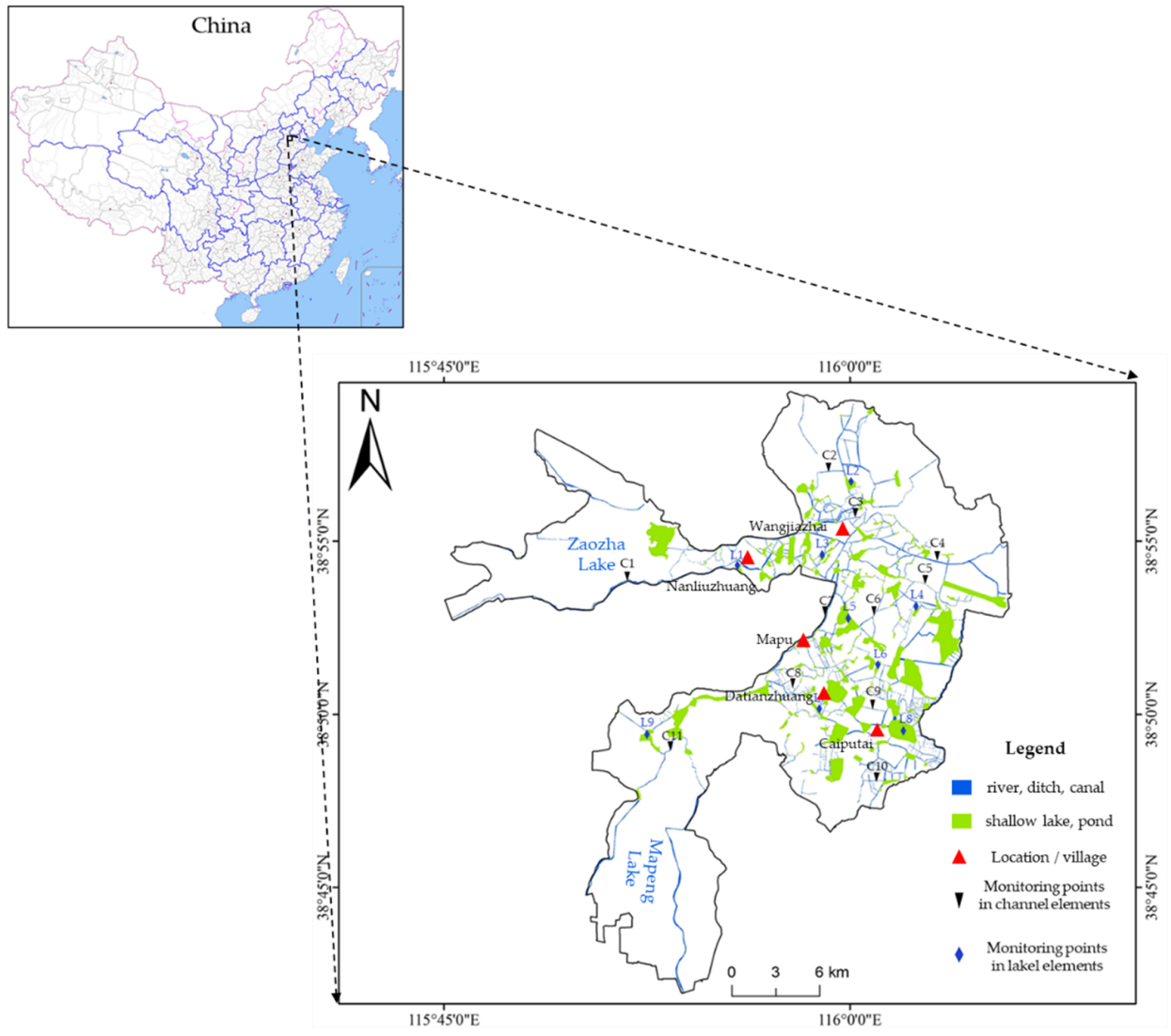

Figure 4. Location of the Baiyangdian Wetland and the study area. 
Table 3. Fish species richness of channel elements.

\begin{tabular}{cccc}
\hline \multirow{2}{*}{ Monitoring Points } & \multicolumn{2}{c}{ Structural Attributes } & \multirow{2}{*}{ Species Richness } \\
\cline { 2 - 3 } & Width & Depth & \\
\hline C1 & 26.9 & 3.8 & 1.67 \\
C2 & 12 & 1.9 & 1.06 \\
C3 & 8 & 1.6 & 0.91 \\
C4 & 38 & 5.8 & 1.80 \\
C5 & 17.3 & 3.4 & 1.23 \\
C6 & 23 & 3.8 & 1.64 \\
C7 & 41 & 4.7 & 1.76 \\
C8 & 5 & 1.1 & 0.74 \\
C9 & 18 & 3.7 & 1.46 \\
C10 & 9 & 2.4 & 1.14 \\
C11 & 23 & 3.6 & 1.50 \\
\hline
\end{tabular}

Table 4. Fish species richness of lake elements.

\begin{tabular}{cccc}
\hline \multirow{2}{*}{ Monitoring Points } & \multicolumn{2}{c}{ Structural Attributes } & \multirow{2}{*}{ Species Richness } \\
\cline { 2 - 3 } & Area & Depth & 1.15 \\
\hline L1 & 0.14 & 1.8 & 1.57 \\
L2 & 0.63 & 2.6 & 0.89 \\
L3 & 0.09 & 1.2 & 1.67 \\
L4 & 0.18 & 3.4 & 2.02 \\
L5 & 1.2 & 4.2 & 1.53 \\
L6 & 0.36 & 1.9 & 1.64 \\
L7 & 0.51 & 3.2 & 2.10 \\
L8 & 1.6 & 4.5 & 1.75 \\
L9 & 0.9 & 2.8 & \\
\hline
\end{tabular}

(a)
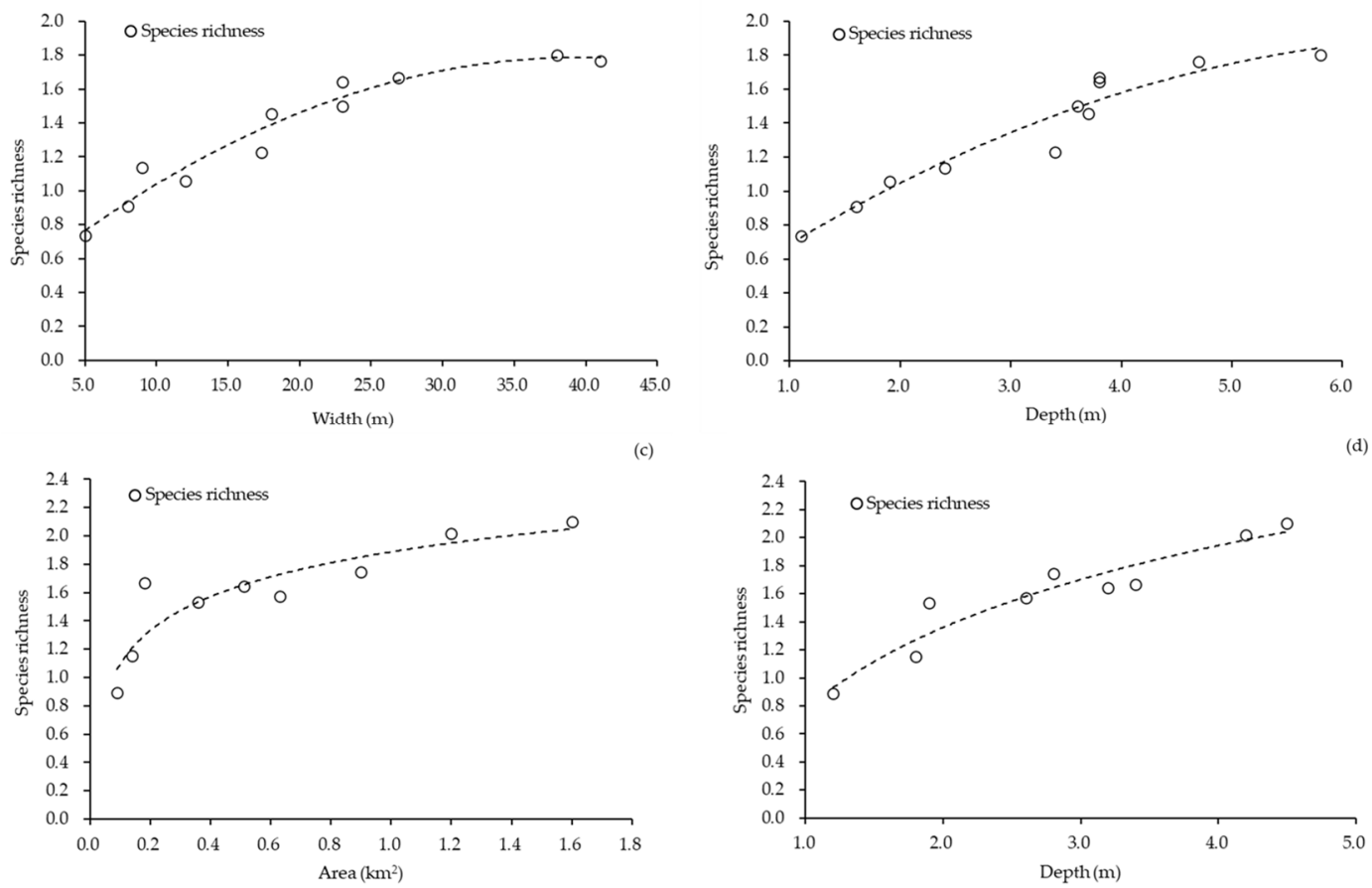

Figure 5. Relationships between structural attributes of elements and species richness. (a,b) is the fitting relationship between channel width, depth; $(\mathbf{c}, \mathbf{d})$ is the fitting relationship between lake area and depth and fish species richness. 
Table 5. Species dominance of channel elements.

\begin{tabular}{|c|c|c|c|c|c|c|c|c|}
\hline \multirow{2}{*}{$\begin{array}{l}\text { Monitoring } \\
\text { Points }\end{array}$} & \multicolumn{8}{|c|}{ Species } \\
\hline & Carassius auratus & Cyprinus carpi & $\begin{array}{l}\text { Pseudobagrus } \\
\text { fulvidraco }\end{array}$ & $\begin{array}{l}\text { Hypophthalmichthys } \\
\text { molitrix }\end{array}$ & $\begin{array}{c}\text { Ctenopharyngodon } \\
\text { idellus }\end{array}$ & Silurus asotus & $\begin{array}{l}\text { Hemiculter } \\
\text { leucisculus }\end{array}$ & $\begin{array}{c}\text { Pseudorasbora } \\
\text { parva }\end{array}$ \\
\hline C1 & 0.11 & 0.26 & 0.10 & 0.28 & 0.00 & 0.00 & 0.38 & 0.33 \\
\hline C3 & 0.23 & 0.00 & 0.00 & 0.00 & 0.00 & 0.13 & 0.78 & 0.69 \\
\hline $\mathrm{C} 4$ & 0.17 & 0.31 & 0.03 & 0.24 & 0.18 & 0.00 & 0.22 & 0.00 \\
\hline C5 & 0.10 & 0.15 & 0.00 & 0.38 & 0.00 & 0.00 & 0.46 & 0.58 \\
\hline C6 & 0.18 & 0.26 & 0.00 & 0.12 & 0.00 & 0.17 & 0.40 & 0.30 \\
\hline C7 & 0.13 & 0.21 & 0.05 & 0.27 & 0.23 & 0.00 & 0.21 & 0.08 \\
\hline C9 & 0.19 & 0.00 & 0.11 & 0.38 & 0.06 & 0.00 & 0.44 & 0.41 \\
\hline $\mathrm{C} 10$ & 0.31 & 0.00 & 0.00 & 0.00 & 0.00 & 0.31 & 0.48 & 0.50 \\
\hline C11 & 0.36 & 0.00 & 0.06 & 0.22 & 0.14 & 0.00 & 0.44 & 0.36 \\
\hline
\end{tabular}

Table 6. Species dominance of lake elements.

\begin{tabular}{|c|c|c|c|c|c|c|c|c|c|c|}
\hline \multirow{2}{*}{$\begin{array}{l}\text { Monitoring } \\
\text { Points }\end{array}$} & \multicolumn{10}{|c|}{ Species } \\
\hline & $\begin{array}{l}\text { Carassius } \\
\text { auratus }\end{array}$ & $\begin{array}{l}\text { Cyprinus } \\
\text { carpi }\end{array}$ & $\begin{array}{l}\text { Pseudobagrus } \\
\text { fulvidraco }\end{array}$ & $\begin{array}{c}\text { Hypophthalmichthys } \\
\text { molitrix }\end{array}$ & $\begin{array}{c}\text { Ctenopharyngodon } \\
\text { idellus }\end{array}$ & $\begin{array}{l}\text { Megalobrama } \\
\text { amblycephala }\end{array}$ & $\begin{array}{l}\text { Silurus } \\
\text { asotus }\end{array}$ & $\begin{array}{l}\text { Hemiculter } \\
\text { leucisculus }\end{array}$ & $\begin{array}{c}\text { Pseudorasbora } \\
\text { parva }\end{array}$ & $\begin{array}{r}\text { Abbottina } \\
\text { rovularis }\end{array}$ \\
\hline L1 & 0.27 & 0.00 & 0.00 & 0.24 & 0.00 & 0.00 & 0.00 & 0.33 & 0.76 & 0.02 \\
\hline L2 & 0.11 & 0.40 & 0.00 & 0.35 & 0.00 & 0.04 & 0.00 & 0.77 & 0.00 & 0.00 \\
\hline L4 & 0.16 & 0.22 & 0.00 & 0.00 & 0.00 & 0.00 & 0.00 & 0.55 & 0.68 & 0.01 \\
\hline L3 & 0.13 & 0.13 & 0.00 & 0.25 & 0.00 & 0.00 & 0.04 & 0.72 & 0.18 & 0.00 \\
\hline L5 & 0.24 & 0.04 & 0.04 & 0.45 & 0.22 & 0.03 & 0.00 & 0.12 & 0.21 & 0.00 \\
\hline L6 & 0.36 & 0.00 & 0.00 & 0.21 & 0.12 & 0.00 & 0.00 & 0.65 & 0.31 & 0.00 \\
\hline L7 & 0.11 & 0.28 & 0.00 & 0.55 & 0.00 & 0.00 & 0.00 & 0.22 & 0.52 & 0.00 \\
\hline L9 & 0.12 & 0.27 & 0.02 & 0.35 & 0.15 & 0.00 & 0.00 & 0.38 & 0.22 & 0.00 \\
\hline
\end{tabular}


From the above results, we can see that the width, depth, and area of river network elements have significant correlation with fish species richness in the Baiyangdian Wetland. The fish species richness increased with the increase of the width and depth of river elements and the area and depth of lake elements, which indicated that the species richness of large network elements was higher than that of medium and small elements. This can be used as the basis for the grading of the network elements. Through the analysis of species dominance, we found that large C. carpio, H. molitrix and C. idellus are mostly distributed in large network elements, whereas medium-sized C. carpio and C. auratus are concentrated in medium network elements, and H. leucisculus and P. parva and other small fish are primarily distributed in small network elements.

According to our analysis of the network's attribute data, we defined the width of rivers and large canals as $>25 \mathrm{~m}$, and their water depth as $>4 \mathrm{~m}$. We defined the width of canals and ditches as 10 to $25 \mathrm{~m}$ and their water depth as 2 to $4 \mathrm{~m}$, and defined the width of small ditches as $<10 \mathrm{~m}$, with a water depth $<2 \mathrm{~m}$. Medium elements had values between the large and small ranges. Table 7 summarizes these criteria for the grades large, medium, and small for the channel elements.

Table 7. Grading standards for the channel elements.

\begin{tabular}{ccc}
\hline Channel Element Grade & Width $w \mathbf{( m )}$ & Water Depth $\boldsymbol{d}(\mathbf{m})$ \\
\hline Large & $w \geq 25$ & $d \geq 4$ \\
\cline { 2 - 3 } Medium & $10 \leq w<25$ & $2 \leq d$ \\
& $w \geq 25$ & $d<4$ \\
\cline { 2 - 3 } Small & $10<w$ & $0<d$ \\
& $10 \leq w<25$ & $d<2$ \\
\hline
\end{tabular}

From the above conclusions, we can see that there is a significant correlation between fish species richness, species dominance and the area and depth of lake elements. We further combined the habitat requirements of $C$. hybrida and A. orientalis to determine the classification standard of elements.

By conducting field investigations and ecological-niche factor analysis model simulations, Zhao [47] concluded that the most suitable habitat area patches for C. hybrida and A. orientalis were 0.1 to $0.2 \mathrm{~km}^{2}$ and 0.2 to $0.5 \mathrm{~km}^{2}$, respectively. According to the structure and diversity of the bird communities in the Baiyangdian Wetland of Hebei Province, which were described in a report published by the Hebei Wildlife Conservation Association in 2007 [45], C. hybrida and A. orientalis mainly nest in lakes with an area $>0.5 \mathrm{~km}^{2}$ and a depth of $>2 \mathrm{~m}$ and search for food in shallow lakes and ponds with an area and depth of $>0.2 \mathrm{~km}^{2}$ and $<2 \mathrm{~m}$, respectively, located within a distance of 1 to $3 \mathrm{~km}$ from their nests. We analysed the attributes of the network elements in the Baiyangdian Wetland on this basis. Shallow lakes usually had an area and depth $>0.5 \mathrm{~km}^{2}$ and $>4 \mathrm{~m}$, respectively, whereas the area and depth of ponds were 0.2 to $0.5 \mathrm{~km}^{2}$ and approximately $2 \mathrm{~m}$, respectively. The grading standards of the area and water depth of lake elements were determined on this basis. Table 8 summarizes these criteria for the grades large, medium, and small for the lake elements.

Table 8. Grading standards for the lake elements.

\begin{tabular}{ccc}
\hline Lake Element Grade & Area $\boldsymbol{a}\left(\mathbf{k m}^{\mathbf{2}}\right)$ & Water Depth $\boldsymbol{d} \mathbf{( m )}$ \\
\hline Large & $a \geq 0.5$ & $d \geq 4$ \\
\cline { 2 - 3 } Medium & $0.2 \leq a<0.5$ & $2 \leq d$ \\
& $a \geq 0.5$ & $d<4$ \\
\cline { 2 - 3 } Small & $a<0.2$ & $0<d$ \\
& $0.2 \leq a<0.5$ & $d<2$ \\
\hline
\end{tabular}


The channel and lake elements were graded according to the grading standards described in the Methods. Table 9 and Figure 6 present the results.

Table 9. Grading results for the Baiyangdian river system network elements.

\begin{tabular}{cccc}
\hline $\begin{array}{c}\text { Channel Element } \\
\text { Grade }\end{array}$ & $\begin{array}{c}\text { Quantity (No. of } \\
\text { Elements) }\end{array}$ & Lake Element Grade & $\begin{array}{c}\text { Quantity (No. of } \\
\text { Elements) }\end{array}$ \\
\hline Large & 67 & Large & 17 \\
Medium & 369 & Medium & 20 \\
Small & 162 & Small & 136 \\
Total & 598 & Total & 173 \\
\hline
\end{tabular}
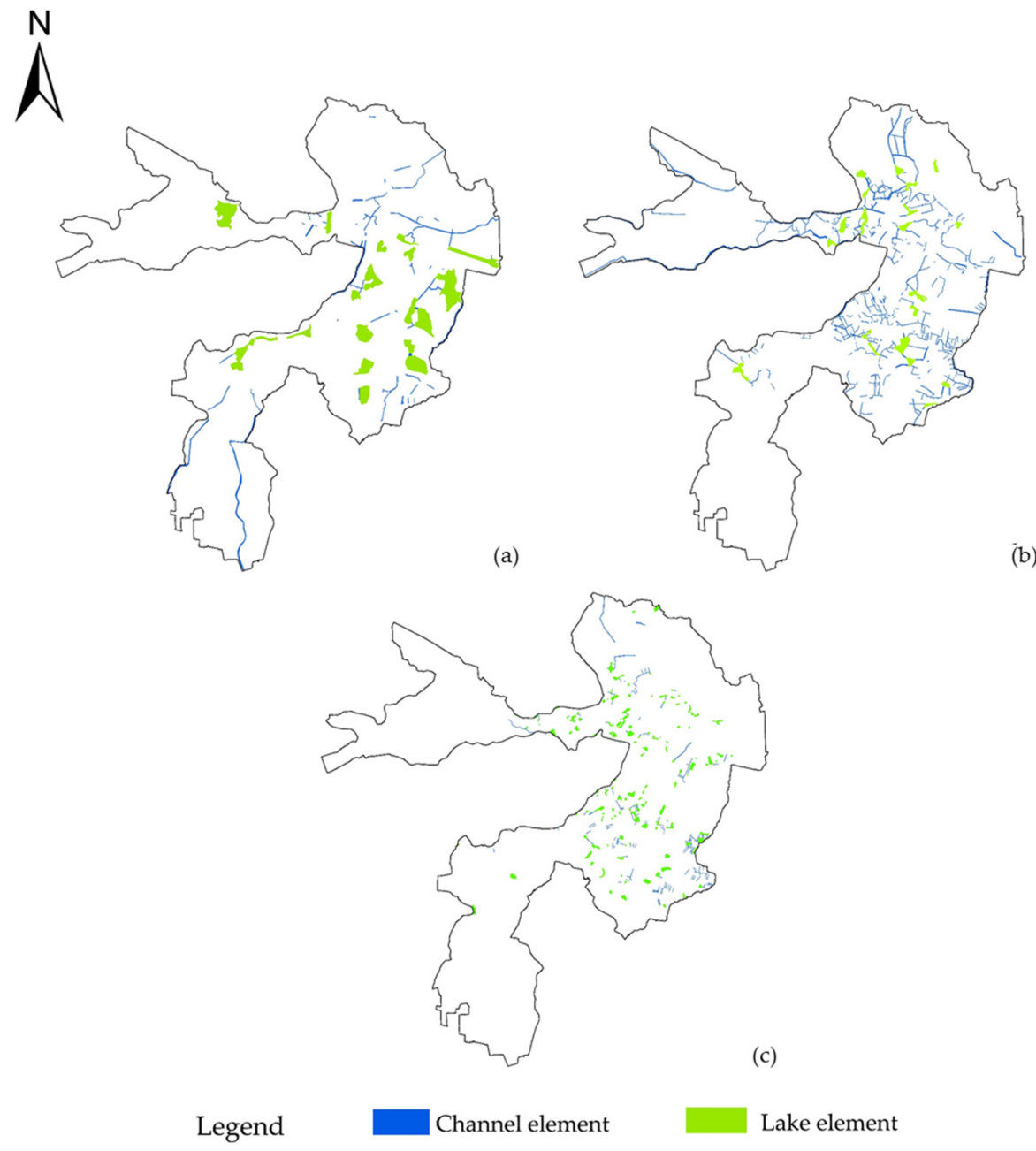

Figure 6. Grading results for the channel and lake elements: (a) large, (b) medium, and (c) small elements based on the criteria in Tables 7 and 8 .

The medium channel elements were most numerous, followed by small channel elements, and large channel elements were the least. The number of medium channel elements was approximately five times that of large channel elements. The small lake elements were most numerous, whereas the numbers of large and medium lake elements were similar, at about $1 / 7$ th the number of small elements. In terms of their spatial distribution, the channel and lake elements were sparsely distributed in the high-elevation Zaozha Lake and Mapeng Lake areas, and were concentrated in the central region of the Baiyangdian Wetland. The large channel and lake elements were few and sparsely distributed, and the combined distribution of the channel and lake elements was bad. For the medium channel and lake elements, the channel elements were much more numerous, 
and the channel elements were densely distributed, with each lake element connected to multiple channel elements; therefore, the combined distribution of channel and lake elements was better. The small channel and lake elements were approximately equally numerous, there are many isolated lake elements, and the channel elements were densely distributed, with the channel elements mostly connected to some lake elements. Overall, the medium channel elements and small lake elements represented the main body of the network and were most widely distributed.

\subsubsection{Grading and Extraction of the Network}

We graded the river system network according to the method in Section 2.1.2, and extracted the networks with different grades using ArcGIS (Figure 7, Table 10).
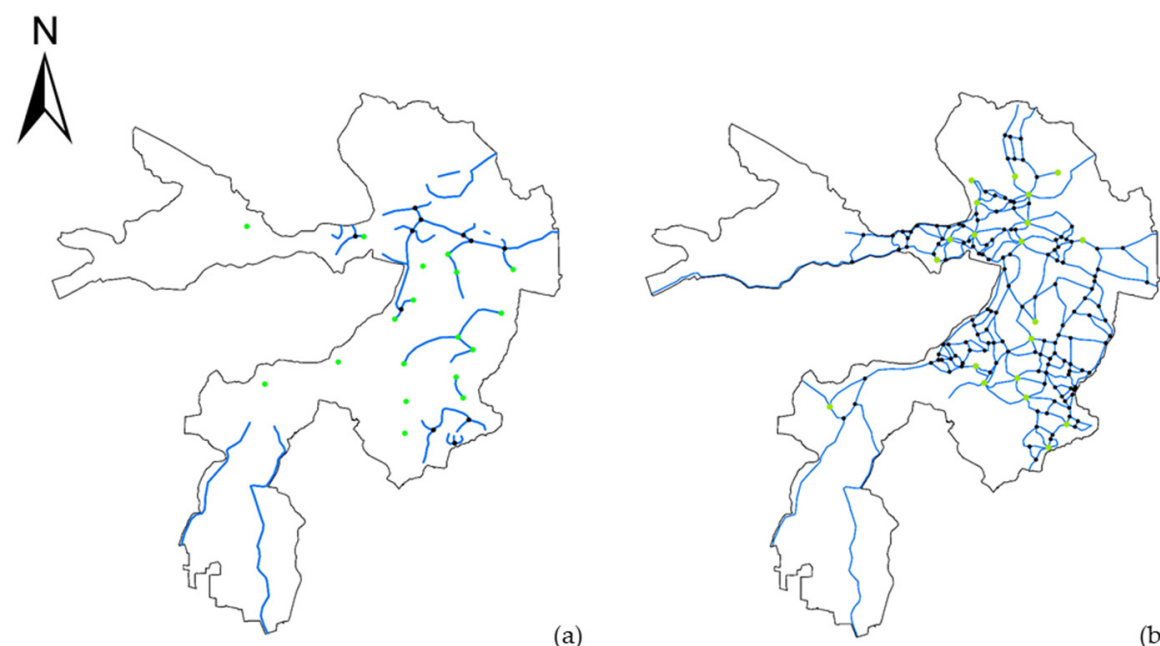

(a)

(b)

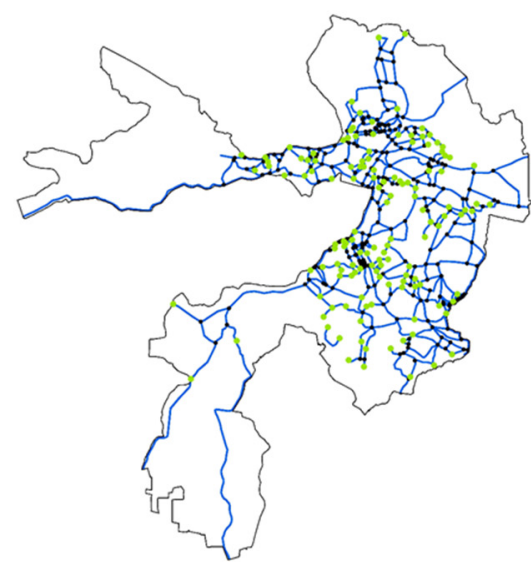

(c)

Legend Edge Node-lake element Node-Intersection

Figure 7. Grading results for the river system networks: (a) large, (b) medium, and (c) small networks.

Table 10. Statistics for the river system network elements with different grades.

\begin{tabular}{cccc}
\hline $\begin{array}{c}\text { Network } \\
\text { Grade }\end{array}$ & Edges (No.) & $\begin{array}{c}\text { Nodes-Lake Element } \\
\text { (No.) }\end{array}$ & $\begin{array}{c}\text { Node-Intersection } \\
\text { (No.) }\end{array}$ \\
\hline Large & 39 & 17 & 11 \\
Medium & 267 & 20 & 144 \\
Small & 534 & 136 & 231 \\
\hline
\end{tabular}

According to the grading results, the numbers of edges and nodes were lowest in large channel-lake networks; many isolated nodes were present and the network exhibited 
the simplest structure. In the medium channel-lake networks, the number of nodes was small but the number of edges was moderately large; the edges and nodes combined and connected to a great extent, forming a complete network. The small channel-lake networks exhibited the largest number of edges and nodes, with many isolated and separated nodes, resulting in a complex network structure.

\subsection{Evaluation of Structural Connectivity}

\subsubsection{Values and Weights of the Indicators}

We calculated the values and weights of all the indicators (Table 11). Large channellake networks had the highest lake element density, followed by the medium network, indicating that the total area of the lake elements was larger than those of the other networks. As the main habitat of waterfowl, large lakes characterised by a large water surface area and dense communities of aquatic plants such as reeds are suitable for nesting. This finding is consistent with the scope of the Baiyangdian Wetland Rare Bird Nature Reserve. Medium channel-lake networks outperformed the other networks in terms of the values of the other six indicators. In the Baiyangdian Wetland, medium channel elements mainly comprised canals and large ditches, which not only function as the main water flow and circulation channels but also serve as the habitat of $C$. carpio and $A$. nobilis. Medium lake elements, with a large surface area and shallow water, provide complete habitat for waterfowl together with large lakes, and they are also the main waterfowl foraging areas. Therefore, a medium channel-lake network forms the main part of the Baiyangdian Wetland and offers the advantages of wide coverage, smooth water circulation, and considerable connectivity; thus, it acts as the carrier of material circulation and the main provider of environmental and ecological functions.

Table 11. Values and weights of the indicators.

\begin{tabular}{|c|c|c|c|c|c|}
\hline \multirow{2}{*}{ Order } & \multirow{2}{*}{ Indicators (Unit) } & \multicolumn{3}{|c|}{ Network Size } & \multirow{2}{*}{ Weigh } \\
\hline & & Large & Medium & Small & \\
\hline 1 & LD (dimensionless) & 0.077 & 0.024 & 0.021 & 0.094 \\
\hline 2 & $\mathrm{C}_{\mathrm{f}}\left(\mathrm{km}^{-2}\right)$ & 0.193 & 1.063 & 0.467 & 0.094 \\
\hline 3 & $\alpha$ (dimensionless) & 0.090 & 0.322 & 0.230 & 0.208 \\
\hline 4 & $\beta$ (dimensionless) & 2.690 & 3.256 & 2.910 & 0.114 \\
\hline 5 & CP (dimensionless) & 0.569 & 0.964 & 0.889 & 0.107 \\
\hline 6 & $\gamma$ (dimensionless) & 0.350 & 0.549 & 0.485 & 0.130 \\
\hline 7 & $\omega$ (dimensionless) & 0.320 & 0.710 & 0.530 & 0.253 \\
\hline
\end{tabular}

\subsubsection{Connectivity Evaluation}

Using the calculation formula in Section 2.2.3, we calculated the structural connectivity index $(I)$ values for the river system networks at different grades. I ranged from 0.538 for large channel-lake networks to 0.895 for the medium networks, with small networks having an intermediate value of 0.718 . The medium networks therefore had the largest structural connectivity. In the medium channel-lake networks, lake elements were less isolated and separated than in the other networks because a large number of evenly distributed channel elements were present. The channel elements were wide and deep, and the smoothness of the water flow was high, ensuring connections among the lake elements and leading to a high overall network connectivity. As the main component of the networks in the Baiyangdian Wetland, the medium channel-lake networks provide fish and waterfowl habitat, and are of considerable importance for biodiversity protection. In the small channel-lake networks, numerous extensively distributed channel and lake elements are available, which should be a basic network in the Baiyangdian Wetland. This grade should have been the network with the optimal connectivity and most frequent exchanges of water and nutrients. But because of the low connectivity index means, the small channellake networks fail to give full play to their potential function as the basic network. The 
lake and channel elements, concentrated in the Nanliuzhuang-Wangjiazhai Village region and the Mapu-Datianzhuang-Caiputai Village region, are the main reason for the poor connectivity of this grade. In the large channel-lake networks, the numbers of channel and lake elements were small, and these elements were sparsely distributed, leaving many isolated lake elements and channel and lake elements that are poorly integrated and that therefore cannot form a complete network. Therefore, the structural connectivity is poor. As the main nesting region of waterfowl and habitat of large fish, the large channel-lake networks fail to effectively provide their full potential environmental and ecological functions due to poor structural connectivity, which reduces the exchanges of water and nutrients, maintenance and improvement of the habitat of species, and protection of biodiversity in the Baiyangdian Wetland.

\section{Discussion}

\subsection{Comparison of Methods}

The in situ monitoring method focuses on the pattern and distribution of the elements of a network, and obtains monitoring data at the intersections of main rivers and lakes to evaluate the network connectivity. It does not account for the differences between the large and small rivers and lakes, and does not establish monitoring stations specifically to account for these differences, and therefore evaluates connectivity as an overall value [19]. The graph theory approach generalises the rivers and lakes in the network into a uniform topological relationship network, and evaluates the connectivity based only on the connection relationships between lines and points [9]. The hydrological model method can account for differences in the hydrological parameters between large and small rivers and lakes in the network through model simulation, but it cannot reveal the connectivity differences between large and small rivers and lakes, and has not been used in a graded system [48]. The connectivity function method evaluates the network connectivity based on landscape changes and differences, and mostly ignores the small elements of the network and landscape units due to limitations on the data accuracy. The multi-indicator comprehensive evaluation method, which is most similar to the method used in the present study, accounts for the structure, function, and processes within the network. It therefore offers a comprehensive evaluation of the network's connectivity, and can reflect the spatial differences and functional differences in the network connectivity, but it ignores the grade characteristics of the network; thus, the accuracy of its connectivity evaluation is insufficient [21]. Although these methods collectively cover all aspects of a network, they individually fail to account for the nonhomogeneous nature of natural systems; both the networks and their elements exhibit significant grade characteristics, and networks with different grades provide different environmental and ecological functions. However, these methods, which mostly uniformly generalise river system networks, do not account for the grade characteristics of the networks. In this paper, we analyze and summarize the existing connectivity evaluation methods, overcome the shortcomings of unified generalisation and evaluation of the network, establish a grading evaluation method of the connectivity of river network system based on the differences of environment and ecological functions, and apply it to a wetland river network system with complex structure, which improves the accuracy of connectivity evaluation. It can provide a more accurate basis for wetland management and ecological environment protection.

\subsection{Comparison of Results}

We compared our evaluation results with the results of previous evaluations of the Baiyangdian Wetland's connectivity by Yan and Niu [49] and Gao et al. [36]. Yan and Niu evaluated the changes of connectivity in the Baiyangdian Wetland from 1990 to 2017 by using the graph theory method. The connectivity index in 2017 was about 0.3 , and the connectivity of network showed a downward trend from 2007 to 2017 [49]. Gao et al. used the multi-indicator comprehensive evaluation method to evaluate the structural connectivity of the Baiyangdian Wetland in 2007 and 2017, and calculated structural 
connectivity index (I) value of 0.432 in 2017, with the connectivity showing a significant downward trend during this 10-year period, which is consistent with the results of Yan and Niu. The analyses by Yan and Niu and by Gao et al. mainly extracted the larger lake and channel elements; Yan and Niu extracted 35 lake elements and 62 channel elements based on data from 2017. Gao et al. extracted 33 lake elements and 57 channel elements based on data from 2017. In the present study, we used 0.2 and $0.4 \mathrm{~km}^{2}$ as the boundaries between small, medium, and large lake elements, and extracted 37 large and medium lake elements ( 2 more than Yan and Niu, 4 more than Gao et al.). We also used a width $>25 \mathrm{~m}$ and a depth $>4 \mathrm{~m}$ as the grade criteria for large channel elements, and extracted 67 large channel elements (5 more than Yan and Niu, 10 more than Gao et al.), which is similar to the number of network elements extracted by Yan and Niu, and Gao et al. The structural connectivity index (I) that we obtained for the large channel-lake river system network was 0.538 , which is close to the results of Gao et al., and Yan and Niu, and the connectivity was rated as poor, which suggests that our results are objective and reliable.

However, unlike the previous research, we went beyond a consideration of the network composed of large rivers, canals, and lakes that are easy to identify and extract; we also evaluated the connectivity of the networks composed of the medium and small elements (369 medium channel elements, 162 small channel elements, and 136 small lake elements) such as small canals, lakes, and ponds that were not included in previous research. The results were $I=0.895$ (medium sizes) and $I=0.718$ (small sizes), which demonstrates that our method accounts for the shortcomings of previous methods that only considered large networks, and thereby provided considerable additional detail on the network and improved the accuracy of our evaluation of the connectivity of the Baiyangdian Wetland. Moreover, we established a grading system for the channel and lake elements and a grading method for the overall network, and used that system to propose a method for the grading evaluation of network connectivity. This overcomes one of the shortcomings of previous methods for unified generalisation of networks and for evaluating the overall connectivity. It therefore provides a more objective and comprehensive method for evaluating river-system network connectivity.

\subsection{Shortcomings of the Method}

In this study, our selection of the grading indexes was a key aspect of the method because different grading indexes may produce different connectivity results. In wetland ecosystems, multiple natural attributes of the network elements, such as water depth, water level, area, discharge, velocity, and water quality can affect environmental and ecological functions. The relationships between these attributes and the network's environmental and ecological functions is highly complex; establishing and describing the relationships between them is therefore difficult. Although the grading indexes we selected account for multiple aspects of the network elements, we focused on structural morphology and did not account for hydrological and water environmental factors such as flow rates and water quality. Thus, our characterisation of the elements was incomplete. Both in our study area and elsewhere, different attributes may be more important in terms of their effect on the environmental and ecological functions provided by the network. The choice of indexes directly influences the grading of the networks and their elements; therefore, identifying the optimal index selection will be an important challenge for future research.

Another problem is that our proposed evaluation method is only applicable to networks whose elements differ considerably in their width, depth, and area. The approach (or the indexes selected) may therefore not be optimal for wetland networks with different characteristics without modifying the approach to account for different key factors. In future research, it will be necessary to consider data on more aspects of the river system network, perhaps by expanding the analysis from the structural indexes used in the present study to hydrologic and ecosystem indexes that account for a wider range of network characteristics. More research on the habitat requirements of key plant and animal species would also improve our method's ability to account for the hydrologic and ecosystem 
factors that are most important for each species. This will improve the generalisability of our method and the accuracy of future evaluations of network connectivity.

\section{Conclusions}

Under the combined effects of human activities and natural evolution, numerous connected rivers, canals, ditches, lakes, and ponds evolve to form complex river system networks. These networks have obvious grade characteristics, with different components of the network performing different environmental and ecological functions. To account for the effect of grade, we established a grading system for the network elements and a grading method for networks, and we constructed a structural connectivity evaluation system. Based on this framework, we propose a method for grading evaluation of riversystem network connectivity accounting for its environmental and ecological functions. We then applied this method to the Baiyangdian Wetland to demonstrate the insights provided by our study, which go beyond most existing evaluation methods, which uniformly generalise the networks and therefore miss key details of the connectivity. Our approach improves on previous methods by providing a more comprehensive evaluation of connectivity. In particular, we accounted for the connectivity characteristics of the small elements of the river system network, which have been ignored in previous research on the Baiyangdian Wetland.

The scientific evaluation of network connectivity will be increasingly important for supporting efforts to maintain or improve wetland environmental and ecological functions. In future research, we should build on the present method to provide better insights into complex natural lake and river systems. Improvements should focus on the grading evaluation; differences in various wetland elements in terms of their morphologies, structures, and hydrology; more thorough exploration of the impact of network connectivity on the environment and ecological functions; improving the scientific rigour and comprehensiveness of the grading system; improving the accuracy and applicability of the method (e.g., to account for the requirements of the species that live in a river network); using the method to provide a more scientific basis for maintaining, improving, or developing wetland networks; and supporting healthier and more sustainable development of wetland ecosystems.

Author Contributions: Conceptualization, K.T. and Y.-w.Z.; data curation, J.B.; methodology, K.T. and Y.-w.Z.; resources, K.T. and Y.-w.Z.; supervision, X.-a.Y. and W.Y.; visualization, K.T. and J.B.; writing—original draft, K.T.; writing—review and editing, X.-a.Y., Y.-w.Z. and W.Y. All authors have read and agreed to the published version of the manuscript.

Funding: We are grateful for funding by the National Natural Science Foundation of China (Grant No. 52070020), the Major Science and Technology Program for Water Pollution Control and Treatment (2018ZX07110001), and the National key research and development program of China (grant 2017YFC0404505).

Institutional Review Board Statement: Not applicable.

Informed Consent Statement: Not applicable.

Data Availability Statement: Data available on request due to restrictions eg privacy or ethical. The data presented in this study are available on request from the corresponding author.

Acknowledgments: We thank Geoffrey Hart for editing the English text of an early draft of this manuscript. We would like to extend special thanks to the editor and the anonymous reviewers for their valuable comments in greatly improving the quality of this paper.

Conflicts of Interest: The authors declare no conflict of interest. The funders had no role in the design of the study; in the collection, analyses, or interpretation of data; in the writing of the manuscript; or in the decision to publish the results. 


\section{References}

1. Costanza, R.; d'Arge, R.; deGroot, R. The value of the world's ecosystem services and natural capital. Nature 1997, 387, 253-260. [CrossRef]

2. Alban, K.; Ant'onio, N.P.; Alvaro, S.-W.; María, D.B.; Luis, G. Ecological impacts of run-of-river hydropower plants-Current status and future prospects on the brink of energy transition. Renew. Sustain. Energy Rev. 2020, 142, 110833.

3. Rogers, K.; Biggs, H. Integrating indicators, endpoints and value systems in strategic management of the rivers of the Kruger National Park. Freshw. Biol. 1999, 41, 439-451. [CrossRef]

4. Shao, X.; Fang, Y.; Jawitz, J.W. River network connectivity and fish diversity. Sci. Total Environ. 2019, 689, 21-30. [CrossRef] [PubMed]

5. Grill, G.; Lehner, B.; Lumsdon, A.E. An index-based framework for assessing patterns and trends in river fragmentation and flow regulation by global dams at multiple scales. Environ. Res. Lett. 2015, 10, 015001. [CrossRef]

6. Suwal, N.; Kuriqi, A.; Huang, X.; Delgado, J.; Młyński, D.; Walega, A. Environmental Flows Assessment in Nepal: The Case of Kaligandaki River. Sustainability 2020, 12, 8766-8769. [CrossRef]

7. Schiemer, F.; Hein, T.; Reckendorfer, W. Ecohydrology, key-concept for large river restoration. Ecohydrol. Hydrobiol. 2007, 7, 101-111. [CrossRef]

8. Lesack, L.F.W.; Marsh, P. River-to-lake connectivities, water renewal, and aquatic habitat diversity in the Mackenzie River Delta. Water Resour. Res. 2010, 46, 45-53. [CrossRef]

9. Meerkerk, A.L.; Wesemael, B.V.; Bellin, N. Application of connectivity theory to model the impact of terrace failure on runoff in semi-arid catchments. Hydrol. Proc. 2010, 23, 2792-2803. [CrossRef]

10. Cui, B.; Wang, C.; Tao, W. River channel network design for drought and flood control: A case study of Xiaoqinghe River Basin, Jinan City, China. J. Environ. Manag. 2009, 90, 3675-3686. [CrossRef]

11. Zhao, J.Y.; Dong, Z.R.; Zhai, Z.L. Evaluation method for river floodplain system connectivity based on graph theory. J. Hydraul. Eng. 2011, 42, 537-543.

12. Bracken, L.J.; Croke, J. The concept of hydrological connectivity and its contribution to understanding runoff-dominated geomorphic systems. Hydrol. Proc. 2007, 21, 1749-1763. [CrossRef]

13. Lane, S.N.; Reaney, S.M.; Heathwaite, A.L. Representation of landscape hydrological connectivity using a topographically driven surface flow index. Water Resour. Res. 2009, 45, 1-10. [CrossRef]

14. Liu, X.; Zhang, Q.; Li, Y. Satellite image-based investigation of the seasonal variations in the hydrological connectivity of a large floodplain (Poyang Lake, China). J. Hydrol. 2020, 585, 124-141. [CrossRef]

15. Shao, X.J.; Fang, Y.; Cui, B.S. A model to evaluate spatiotemporal variations of hydrological connectivity on a basin-scale complex river network with intensive human activity. Sci. Total Environ. 2020, 723, 138-153. [CrossRef]

16. Chen, J.; Xiao, C.; Chen, D. Connectivity evaluation and planning of a river-lake system in east China based on graph theory. Math. Probl. Eng. 2018, 33, 31-42. [CrossRef]

17. Chen, Y.; Wang, Y.G. Changes in river connectivity indexes in the lower Yellow River between 1960 and 2015. River Res. Appl. 2019, 35, 1377-1386. [CrossRef]

18. Godsey, S.E.; Kirchner, J.W. Dynamic, discontinuous stream networks: Hydrologically driven variations in active drainage density, flowing channels and stream order. Hydrol. Proc. 2015, 28, 5791-5803. [CrossRef]

19. Gao, C.J.; Gao, X.C.; Jia, P. Summary comments on hydrologic connectivity. Chin. J. Appl. Environ. Biol. 2017, $23,586-594$.

20. Racchetti, E.; Bartoli, M.; Soana, E. Influence of hydrological connectivity of riverine wetlands on nitrogen removal via denitrification. Biogeochemistry 2011, 103, 335-354. [CrossRef]

21. Xia, M.; Zhou, Z.; Zhao, H.X. Evaluation of water system connectivity of district around Chaohu Lake based on comprehensive index. Geo. Geo Inf. Sci. 2017, 33, 73-77.

22. Detenbeck, N.E.; Elonen, C.M.; Taylor, D.L.; Anderson, T.M.; Jicha, S.L.; Batterman, S.L. Effects of hydrogeomorphic region, catchment storage and mature forest on baseflow and snowmelt stream water quality in second-order Lake Superior basin tributaries. Freshw. Biol. 2003, 48, 912-927. [CrossRef]

23. Fullerton, A.H.; Burnett, K.M.; Steel, R.L.; Filtcroft, G.R.; Pess, B.E.; Feist, C.E. Hydrological connectivity for riverine fish: Measurement challenges and research opportunities. Freshw. Biol. 2010, 55, 2215-2237. [CrossRef]

24. Keller, D.; Holderegger, R.; Van Strien, M.J. Spatial scale affects landscape genetic analysis of a wetland grasshopper. Mol. Ecol. 2013, 22, 2467-2482. [CrossRef]

25. Zeug, S.C.; Winemiller, K.O. Relationships between hydrology, spatial heterogeneity, and fish recruitment dynamics in a temperate floodplain river. River Res. Appl. 2008, 24, 90-102. [CrossRef]

26. Madenjian, C.P.; Bunnell, D.B. Depth distribution dynamics of the sculpin community in Lake Michigan. Trans. Am. Fish. Soc. 2008, 137, 1346-1357. [CrossRef]

27. $\mathrm{Xu}, \mathrm{W}$; Shen, Q.; Wang, X. Sensing images for assessing the minimum ecological flux by automatically extracting river surface width. Remote Sens. 2020, 12, 2899. [CrossRef]

28. Liu, F.; Wang, J.L.; Fu, Z.S. Comparative research on effects of ecological ditches different in specification treating pollutants in drainage. Acta Pedol. Sin. 2019, 36, 562-569.

29. Zheng, B.H.; Zhang, Y.; Li, Y.B. Study of indicators and method assessment of Liao River Basin. Acta Sci. Circum. 2007, 27, 928-936. 
30. Kail, J.; Brabec, K.; Poppe, M.; Januschke, K. The effect of river restoration on fish, macroinvertebrates and aquatic macrophytes: A meta-analysis. Ecol. Indic. 2015, 58, 311-321. [CrossRef]

31. Feyrer, F.; Sommer, T.R.; Zeug, S.C.; O'Leary, G. Fish assemblages of perennial floodplain ponds of the Sacramento River, California (USA) with implications for the conservation of native fishes. Fish. Manag. Ecol. 2004, 24, 335-344. [CrossRef]

32. Roozen, F.C.J.M.; Van Geest, G.J.; Ibelings, B.W. Lake age and water level affect the turbidity of floodplain lakes along the lower Rhine. Freshw. Biol. 2003, 48, 519-531. [CrossRef]

33. Miranda, L.E. Depth as an organizer of fish assemblages in floodplain lakes. Aquat. Sci. 2011, 73, 211-221. [CrossRef]

34. Cohen, M.J.; Brown, M.T. A model examining hierarchical wetland networks for watershed stormwater management. Ecol. Model. 2007, 201, 179-193. [CrossRef]

35. Sun, C.; Knig, H.J.; Sanda, U.; Cheng, C.; Karoline, H. Protection effect of overwintering water bird habitat and defining the conservation priority area in Poyang Lake wetland, China. Environ. Res. Lett. 2020, 15, 125013. [CrossRef]

36. Dodson, S. Predicting crustacean zooplankton species richnes. Limnol. Oceanogr. 1992, 37, 123-131. [CrossRef]

37. Gao, T.; Yin, X.A.; He, S.; Zhao, Y.W. Structural connectivity evaluation of Baiyangdian water system. J. Hydrol. $2020,41,63-69$.

38. Xu, G.L.; Xu, Y.P.; Wang, L.Y. Evaluation of river network connectivity based on hydraulic resistance and graph theory. Adv. Water Sci 2012, 23, 776-781.

39. Saaty, T.L. The Analytic Hierarchy Process: Planning, Priority Setting; McGraw-Hill: New York, NY, USA, 1980.

40. Delgado, A.; Romero, I. Environmental conflict analysis using an integrated grey clustering and entropy-weight method: A case study of a mining project in Peru. Environ. Model. Softw. 2016, 77, 108-121. [CrossRef]

41. Miranda, L.E.; Killgore, K.J. Fish depth distributions in the Lower Mississippi River. River Res. Appl. 2014, 30, 347-359. [CrossRef]

42. Xie, S.; He, H.D. Present condition analysis of Hebei Baiyangdian lake fish stocks after diversion from Yellow River to the lake. Sci. Tech. Inform. 2010, 23, 433-436.

43. Wang, Y.H.; Wu, T.T.; Fan, J.G. Hou Jianhua Avian community and group diversity of Baiyangdian Lake in summer. J. Hebei Univ. Nat. Sci. Ed. 2018, 38, 443-448.

44. Du, H.; Ban, X.; Zhang, H.; Wei, Q.W.; Chen, D.Q. Preliminary observation on preference of fish in natural channel to water depth and velocity-A case study of the Yangtze River from Jiang Kou town to Yuan Shi town. J. Yangtze River Sci. Res. Inst. 2010, 27, 70-74.

45. Gilbert, G.; Tyler, G.A.; Dunn, C.J.; Smith, K.W. Nesting habitat selection by bitterns Botaurus stellaris in Britain and the implications for wetland management. Biol. Conserv. 2005, 124, 547-553. [CrossRef]

46. China Biodiversity Conservation and Green Development Foundation. Rapid Assessment in Research of Wild Fish Resource in Baiyangdian Wetland and Sustainable Utilization; CBCGDF: BaoDing, China, 2017.

47. Zhao, Z.X. Coupling Mechanism of Eco-Hydrological Processes and Integrated Regulation in Baiyangdian Wetland. Ph.D. Thesis, Tianjin University, Tianjin, China, 2012.

48. Wu, M.L. The Study on Structure and Diversity of Bird Communities in the Baiyangdian Wetland of Hebei Province Hebei; Hebei Wildlife Protection Association: Shijiazhuang, China, 2007; pp. 70-78.

49. Yan, X.; Niu, Z.G. Spatial-temporal Variation Characteristics of Baiyangdian from 1990 to 2017. Chin. J. Wet. Sci. 2019, 17, 436-444. 